SAINTIFIK, Vol.5, No.1, Januari 2019, pp. 36 43

ISSN 2407-4098 (print)

ISSN 2622-8904 (online)

\title{
Beberapa Sifat Akar Persamaan Kuadrat Berkoefisien Bilangan Kompleks
}

\author{
Ahmad Ansar*1, Muhammad Arafat Abdullah ${ }^{2}$ \\ ${ }^{1,2}$ Universitas Sulawesi Barat \\ e-mail: *11 ahmad.ansar@unsulbar.ac.id, ${ }^{2}$ arafat@unsulbar.ac.id
}

\begin{abstract}
Abstrak
Pada makalah ini dibahas dan diselidiki sifat akar-akar persamaan kuadrat berkoefisien kompleks. Diawali dengan mempelajari cara menentukan akar-akar persamaan kuadrat berkoefisien kompleks. Hasil yang diperoleh digunakan untuk menyelidiki syarat persamaan kuadrat berkoefisien kompleks memiliki akar sama, akar-akar yang saling konjugat, memiliki sebuah akar real serta memiliki sebuah akar imajiner murni. Dijelaskan pula cara membentuk persamaan kuadrat baru apabila diketahui akar-akarnya.
\end{abstract}

Kata kunci : Persamaan kuadrat, Koefisien kompleks, Bilangan Kompleks

\section{PENDAHULUAN}

Perkembangan sistem bilangan dimulai sejak manusia mengenal bilangan asli untuk menghitung banyaknya hewan ternak yang mereka miliki hingga sistem bilangan real. Bilangan real terdiri dari bilangan rasional dan bilangan irrasional. Setelah mengenal sistem bilangan, dikembangkanlah persamaan matematika yang digunakan untuk membantu menyelesaiakan atau mencari solusi dari masalah-masalah nyata yang dihadapi manusia.

Salah satu persamaan matematika yang banyak dikenal dan digunakan dalam matematika adalah persamaan kuadrat, yaitu persamaan yang berbentuk $a x^{2}+b x+c=0$, dengan $a, b, c \in \mathbf{R}$. Nilai-nilai $x$ yang memenuhi persamaan kuadrat disebut akar persamaan kuadrat. Metode menentukan akar-akar persamaan kuadrat dibahas oleh Al-Khwarismi dalam bukunya Algebra yang banyak digunakan hari ini dalam Merino (2006). Selanjutnya, metode aljabar yang dikembangkan oleh Al-Khwarismi diterjemahkan oleh Gerard of Cremona dan Leonardo da Pisa (Fibonacci) ke dalam bahasa Latin.

Dalam Waerden (1985) dijelaskan bahwa Gerolamo Cardano menemukan solusi untuk mencari akar-akar persamaan kubik dan memperkenalkan bilangan baru seperti $5+\sqrt{-15}$ dan $5-\sqrt{-15}$ sebagai solusi dari persamaan kubik. Selanjutnya, Rafael Bombelli memperkenalkan notasi $\sqrt{-1}$ yang disebut "pi'u di meno" serta Leonhard Euler pertama kali meperkenalkan notasi $i=\sqrt{-1}$ yang disebut bilangan imajiner. Dengan dikenalnya bilangan imajiner, maka dikembangkanlah himpunan bilangan kompleks.

Himpunan bilangan kompleks menjadi penting karena setiap suku banyak berdarajat $n$ akan selalu mempunyai akar sebanyak $n$ yang akar-akarnya merupakan bilangan kompleks. Hal ini telah di buktikan oleh Carl F. Gauss dalam disertasi doktornya tahun 1799. Dalam banyak literature, pembahasan tentang suku banyak lebih berfokus pada suku banyak berkoefisien bilangan real. Sementara dalam beberapa kasus dibutuhkan juga penjelasan mengenai suku banyak berkoefisien kompleks.

Dalam tulisan ini akan dikaji tentang suku banyak berderajat dua atau persamaan kuadrat yang berkoefisien kompleks yang merupakan perumuman dari persamaan kuadrat berkoefisien real. Dalam kajian ini akan dijelaskan cara menentukan akar-akar persamaan

Received November 11 $1^{\text {st }}, 2018$; Revised December 15 ${ }^{\text {th }}, 2018$; Accepted December $30^{\text {th }}, 2018$ 
kuadrat berkoefisien kompleks serta beberapa sifat dari akar-akar tersebut. Selanjutnya, dijelaskan pula cara menentukan persamaan kuadrat baru yang diketahui akar-akarnya.

\section{METODE PENELITIAN}

Metode yang digunakan dalam penelitian ini adalah penelitian studi literatur. Metode ini dilakukan dengan mengumpulkan dan mengkaji makalah-makalah serta buku-buku yang relevan dengan persamaan kuadrat koefisien kompleks. Hasil dari kajian tersebut akan menjadi landasan dalam menentukan akar-akar persamaan kuadrat koefisien kompleks dan sifat-sifatnya. Selanjutnya, akan diselidiki cara menentukan persamaan kuadrat baru yang diketahui akarakarnya

\section{HASIL DAN PEMBAHASAN}

Pada bagian ini, penjelasan diawali dengan definisi bilangan kompleks, serta suku banyak berkoefisien kompleks. Lebih lanjut, akan dibahas cara menentukan akar-akar persamaan kuadrat koefisien kompleks dan sifat-sifatnya.

\subsection{Bilangan Kompleks}

Dalam Zill dan Shanahan (2003) diberikan definisi bilangan kompleks.

\section{Definisi 3.1.}

Bilangan kompleks adalah bilangan yang berbentuk

$$
z=a+i b
$$

dengan $a, b \in \mathbf{R}$ dan $i$ adalah imajiner satuan.

Bilangan imajiner satuan $i=\sqrt{-1}$ memiliki sifat $i^{2}=-1$. Jika $z=a+i b$ maka $a$ disebut sebagai bagian real dari $z$ dan ditulis $\operatorname{Re}(z)=a$ serta $b$ disebut sebagai bagian imajiner dari $z$ dan ditulis $\operatorname{Im}(z)=b$. Himpunan semua bilangan kompleks dinotasikan $\mathbf{C}$ yaitu

$$
\mathbf{C}=\{z=a+i b \mid a \in \mathbf{R} \text { dan } b \in \mathbf{R}\}
$$

Jika $\operatorname{Im}(z)=0$, maka $z=a \in \mathbf{R}$ dan jika $\operatorname{Re}(z)=0$, maka $z=b i \in \mathbf{C}$ dan disebut bilangan imajiner murni.

\section{Definisi 3.2}

Diberikan bilangan kompleks $z=a+i b$. Konjugat dari bilangan kompleks $z$, ditulis $\bar{z}$, didefinisikan sebagai $z=a-i b$.

Dalam Barnett, dkk (2009) dan Sullivan (2012) diberikan definisi suku banyak dan Teorema Fundamental Aljabar.

\section{Definisi 3.3}

Fungsi suku banyak $f$ yang berderajat $n$ adalah fungsi yang berbentuk

$$
f(x)=a_{n} x^{n}+a_{n-1} x^{n-1}+\cdots+a_{1} x+a_{0}
$$

dengan $a_{n}, a_{n-1}, \cdots, a_{1}, a_{0} \in \mathbf{C}, a_{n} \neq 0, n \in \mathbf{N}$, dan $x \in \mathbf{C}$.

Teorema 3.4. (Teorema Fundamental Aljabar)

Setiap suku banyak berderajat $n$ mempunyai solusi sebnayak $n$ yang merupakan bilangan kompleks.

\section{Contoh 3.5}


Diberikan suku banyak $i x^{5}-(4-i) x^{3}+2 x^{2}+(1+2 i) x=0$ merupakan suku banyak berderjat 5 , sehingga mempunyai solusi sebanyak 5 buah bilangan kompleks.

\subsection{Akar-akar Persamaan Kuadrat Koefisien Kompleks}

Dalam Andreescu dan Andrica (2010) dijelaskan cara menentukan solusi persamaan kuadrat berkoefisien kompleks. Diberikan persamaan kuadrat dengan koefisien bilangan kompleks

dengan $a, b, c \in \mathbf{C}$ dan $a \neq 0$.

$$
a z^{2}+b z+c=0
$$

Dengan manipulasi aljabar diperoleh

$$
\left(z+\frac{b}{2 a}\right)^{2}=\frac{b^{2}-4 a c}{4 a^{2}}
$$

Ekuivalen dengan

$$
4 a^{2} z^{2}+4 a b z+b^{2}=b^{2}-4 a c
$$

Selanjutnya, $b^{2}-4 a c$ disebut diskriminan dari persamaan (4) dan ditulis $D=b^{2}-4 a c$. Misalkan $w=2 a z+b$, diperoleh

dengan $u, v \in \mathbf{R}$.

$$
w^{2}=D=u+i v
$$

Dari persamaan (7), diperoleh

$$
v=\operatorname{sign}(v) \sqrt{|D|^{2}-u^{2}}
$$

dimana $\operatorname{sign}(v)$ menyatakan tanda bilangan real $v$. Selanjutnya, dari persamaan (7) dan (8) diperoleh

$$
w_{1 ; 2}= \pm\left(\sqrt{\frac{|D|+u}{2}}+\operatorname{sign}(v) \sqrt{\frac{|D|-u}{2} i}\right)
$$

Akibatnya,

$$
z_{1 ; 2}=\frac{1}{2 a}\left(-b+w_{1 ; 2}\right)
$$

Jadi akar-akar persamaan kuadrat $a z^{2}+b z+c=0$ dapat dicari dengan rumus $z_{1 ; 2}=\frac{1}{2 a}\left(-b+w_{1 ; 2}\right)$.

\section{Contoh 3.6}

Persamaan kuadrat $2 i z^{2}+(2-14 i) z-(8-24 i)=0$ adalah persamaan kuadrat berkoefisien bilangan kompleks.

Beradasarkan persamaan kuadrat di atas diperoleh $D=8 i$ dan $|D|=8$. Oleh karena itu,

$$
\begin{aligned}
w_{1 ; 2} & = \pm\left(\sqrt{\frac{8+0}{2}}+\sqrt{\frac{8-0}{2}} i\right) \\
& = \pm(2+2 i)
\end{aligned}
$$

Diperoleh

$$
\begin{aligned}
z_{1 ; 2} & =\frac{1}{2 a}\left(-b+w_{1 ; 2}\right) \\
& =\frac{1}{4 i}(-(2-14 i) \pm(2+2 i))
\end{aligned}
$$

Jadi $z_{1}=4$ dan $z_{2}=3+i$. 


\subsection{Sifat Akar Persamaan Kuadrat Koefisien Kompleks} kompleks.

Berikut diberikan beberapa teorema terkait akar-akar persamaan kuadrat berkoefisien

\section{Teorema 3.7}

Jika $z_{1}$ adalah akar persamaan kuadrat $a z^{2}+b z+c=0$ dengan $a, b, c \in \mathbf{R}$ dan $a \neq 0$, maka $z_{2}=\bar{z}_{1}$ juga merupakan akar persamaan kuadrat.

\section{Bukti:}

Misalkan $z_{1}$ adalah akar persamaan kuadrat $a z^{2}+b z+c=0$, berarti $a z_{1}^{2}+b z_{1}+c=0$. Dengan operasi konjugat, diperoleh,

$$
a \bar{z}_{1}^{2}+b \bar{z}_{1}+c=0
$$

Jadi $\bar{z}_{1}$ juga merupakan akar persamaan kuadrat $a z^{2}+b z+c=0$ dengan $a, b, c \in \mathbf{R}$ dan $a \neq 0$.

\section{Akibat 3.8}

Jika $z_{1}$ adalah akar persamaan kuadrat $a z^{2}+b z+c=0$ dengan $a, b, c \in \mathbf{C} \mathbf{R}$ dan $a \neq 0$, maka $z_{2}=\bar{z}_{1}$ bukan merupakan akar persamaan kuadrat.

\section{Bukti:}

Misalkan $z_{1}$ adalah akar persamaan kuadrat $a z^{2}+b z+c=0$, berarti $a z_{1}^{2}+b z_{1}+c=0$. Dengan operasi konjugat, diperoleh,

$$
\overline{a z}_{1}^{2}+\bar{b} \bar{z}_{1}+\bar{c}=0
$$

Karena $a, b, c \in \mathbf{C} \mathbf{R}$, maka $a \neq \bar{a}, b \neq \bar{b}$ dan $c \neq \bar{c}$. Akibatnya, $\bar{z}_{1}$ bukan akar persamaan kuadrat $a z^{2}+b z+c=0$.

Selanjutnya, akan dijelaskan syarat suatu persamaan kuadart $a z^{2}+b z+c=0$ dengan $a, b, c \in \mathbf{C}$ dan $a \neq 0$ memiliki akar-akar yang sama, akar kompleks yang saling konjugat, serta akar yang saling berkebalikan.

\section{Teorema 3.9}

Persamaan kuadart $a z^{2}+b z+c=0$ dengan $a, b, c \in \mathbf{C}$ dan $a \neq 0$ memiliki akar-akar yang sama jika dan hanya jika $b^{2}=4 a c$.

\section{Bukti:}

$\Rightarrow$ ) Diberikan persamaan kuadart $a z^{2}+b z+c=0$ dengan $a, b, c \in \mathbf{C}$ dan $a \neq 0$ memiliki akarakar $z_{1}$ dan $z_{2}$. Karena $z_{1}=z_{2}$, berdasarkan persamaan (10), maka $w_{1}=w_{2}$. Diperoleh

$$
\left(\sqrt{\frac{|D|+u}{2}}+\operatorname{sign}(v) \sqrt{\frac{|D|-u}{2}} i\right)+\left(\sqrt{\frac{|D|+u}{2}}+\operatorname{sign}(v) \sqrt{\frac{|D|-u}{2}} i\right)=0
$$

Akibatnya, $|D|=0$ atau $b^{2}=4 a c$. Jadi persamaan persamaan kuadart $a z^{2}+b z+c=0$ akan memiliki akar yang sama apabila $b^{2}=4 a c$.

$\Leftarrow)$ Karena $b^{2}=4 a c$ berarti $D=0$. Diperoleh $u=0$. Akibatnya $w_{1 ; 2}=0$. Oleh karena itu,

$$
\begin{aligned}
z_{1 ; 2} & =\frac{1}{2 a}\left(-b+w_{1 ; 2}\right) \\
& =\frac{-b}{2 a}
\end{aligned}
$$

Jadi. persamaan kuadart $a z^{2}+b z+c=0$ mempunyai akar-akar yang sama. 


\section{Teorema 3.10}

Diberikan persamaan kuadrat $a z^{2}+b z+c=0$ dengan $a \neq 0$. Jika $a, b, c \in \mathbf{R}$ dan $b^{2}<4 a c$, maka persamaan kuadrat tersebut memiliki akar-akar berupa bilangan kompleks yang saling konjugat.

\section{Bukti:}

Diketahui $a, b, c \in \mathbf{R}$, berdasarkan Teorema 3.9, maka persamaan kuadrat $a z^{2}+b z+c=0$ memiliki akar-akar saling konjugat. Selanjutnya, karena $b^{2}<4 a c$, berarti $D<0$. Diperoleh $|D|=-u$. Akibatnya, $w_{1: 2} \in \mathbf{C}$. Karena $a, b \in \mathbf{R}$, maka $z_{1 ; 2} \in \mathbf{C}$. Jadi persamaan kuadrat $a z^{2}+b z+c=0$ mempunyai akar-akar bilangan kompleks yang saling konjugat.

\section{Teorema 3.11}

Persamaan kuadart $a z^{2}+b z+c=0$ dengan $a, b, c \in \mathbf{C}$ dan $a \neq 0$ memiliki akar-akar $z_{1}, z_{2} \in \mathbf{C}$. Nilai $z_{1}=\frac{1}{z_{2}}$ jika dan hanya jika $a=c$.

\section{Bukti:}

$\Rightarrow$ ) Diberikan persamaan kuadart $a z^{2}+b z+c=0$ dengan $a, b, c \in \mathbf{C}$ dan $a \neq 0$ memiliki akarakar $z_{1}$ dan $z_{2}$. Diperoleh

$$
a z_{1}^{2}+b z_{1}+c=0 \text { dan } a z_{2}^{2}+b z_{2}+c=0
$$

Karena $z_{1}=\frac{1}{z_{2}}$, maka

$$
\begin{aligned}
& a\left(\frac{1}{z_{2}}\right)^{2}+b \frac{1}{z_{2}}+c=0 \\
& a+b z_{2}+c z_{2}^{2}=0
\end{aligned}
$$

Berdasarkan persamaan (17) dan (18) diperoleh $a=c$.

$\Leftrightarrow$ ) Diketahui $a=c$ berarti $c z_{2}^{2}+b z_{2}+a=0$. Akibatnya,

$$
\begin{aligned}
& c z_{2}^{2}+b z_{2}+a=0 \\
& c+\frac{b}{z_{2}}+\frac{a}{z_{2}^{2}}=0
\end{aligned}
$$

Karena $a z_{1}^{2}+b z_{1}+c=0$, maka $z_{1}=\frac{1}{z_{2}}$.

Selanjutnya, dijelaskan mengenai persamaan kuadrat yang memiliki sebuah akar real dan persamaan kuadrat yang memiliki sebuah akar imajiner murni.

Persamaan kuadrat $a z^{2}+b z+c=0$ dengan $a, b, c \in \mathbf{C}$ dan $a \neq 0$ dapat ditulis menjadi

$$
z^{2}+\frac{b}{a} z+\frac{c}{a}=0
$$

Misalkan $\frac{b}{a}=p+q i$ dan $\frac{c}{a}=r+s i$ dengan $p, q, r, s \in \mathbf{R}$. Diperoleh

$$
z^{2}+(p+q i) z+(r+s i)=0
$$

Misalkan persamaan kuadrat $z^{2}+(p+q i) z+(r+s i)=0$ memiliki sebuah akar real yaitu $z_{1}$, sehingga $z_{1}^{2}+(p+q i) z_{1}+(r+s i)=0$. Diperoleh $z_{1}^{2}+p z_{1}+r=0$ dan $q z_{1}+s=0$. Akibatnya,

$$
\begin{aligned}
& \left(\frac{-s}{q}\right)^{2}+p\left(\frac{-s}{q}\right)+r=0 \\
& s^{2}-p s q+r q^{2}=0
\end{aligned}
$$


Jadi agar persamaan kuadrat $z^{2}+(p+q i) z+(r+s i)=0$ memiliki sebuah akar real maka haruslah dipenuhi $s^{2}-p s q+r q^{2}=0$.

Misalkan persamaan kuadrat $z^{2}+(p+q i) z+(r+s i)=0$ memiliki sebuah akar imajiner murni yaitu $z_{1}=i y$, sehingga $(i y)^{2}+(p+q i)(i y)+(r+s i)=0$. Diperoleh $-y^{2}-q y+r=0$ dan $p y+s=0$. Akibatnya,

$$
\begin{aligned}
& \left(\frac{-s}{p}\right)^{2}-q\left(\frac{-s}{p}\right)+r=0 \\
& -s^{2}+p s q+r p^{2}=0
\end{aligned}
$$

Jadi agar persamaan kuadrat $z^{2}+(p+q i) z+(r+s i)=0$ memiliki sebuah akar imajiner murni maka haruslah dipenuhi $-s^{2}+p s q+r p^{2}=0$.

\section{Remark:}

Persamaan kuadrat $a z^{2}+b z+c=0$ dengan $a \neq 0$ akan memiliki dua buah akar real apabila $a, b, c \in \mathbf{R}$ dan $b^{2}>4 a c$.

\subsection{Membentuk Persamaan Kuadrat Baru}

Berdasarkan persamaan (10) dapat dicari nilai dari $z_{1}+z_{2}$, yaitu

$$
\begin{aligned}
z_{1}+z_{2} & =\frac{1}{2 a}\left(-b+\left(\sqrt{\frac{|D|+u}{2}}+\operatorname{sign}(v) \sqrt{\frac{|D|-u}{2}} i\right)\right)+\frac{1}{2 a}\left(-b-\left(\sqrt{\frac{|D|+u}{2}}+\operatorname{sign}(v) \sqrt{\frac{|D|-u}{2}} i\right)\right) \\
& =\frac{-b}{a}
\end{aligned}
$$

Selanjutnya, untuk $z_{1} \cdot z_{2}$, yaitu

$$
\begin{aligned}
z_{1} \cdot z_{2} & =\frac{1}{2 a}\left(-b+\left(\sqrt{\frac{|D|+u}{2}}+\operatorname{sign}(v) \sqrt{\frac{|D|-u}{2}} i\right)\right) \cdot \frac{1}{2 a}\left(-b-\left(\sqrt{\frac{|D|+u}{2}}+\operatorname{sign}(v) \sqrt{\frac{|D|-u}{2}} i\right)\right) \\
& =\frac{1}{4 a^{2}}\left(b^{2}-\left(u+\operatorname{sign}(v) i \sqrt{|D|^{2}-u^{2}}\right)\right) \\
& =\frac{1}{4 a^{2}}\left(b^{2}-(u+v i)\right) \\
& =\frac{1}{4 a^{2}}\left(b^{2}-\left(b^{2}-4 a c\right)\right) \\
& =\frac{c}{a}
\end{aligned}
$$

Jadi diperoleh $z_{1}+z_{2}=\frac{-b}{a}$ dan $z_{1} \cdot z_{2}=\frac{c}{a}$.

Misalkan $z_{1}$ dan $z_{2}$ adalah akar-akar persamaan kuadrat, maka dapat dibentuk persamaan kuadrat baru dengan rumus

$$
\left(z-z_{1}\right)\left(z-z_{2}\right)=0 \Leftrightarrow z^{2}-\left(z_{1}+z_{2}\right) z+z_{1} \cdot z_{2}=0
$$

Bentuk di atas dapat diperluas untuk, menentukan suatu persamaan kuadrat baru yang akarakarnya berhubungan dengan persamaan kuadarat yang lain. Misalkan persamaan kuadrat $a z^{2}+b z+c=0$ dengan $a, b, c \in \mathbf{C}$ dan $a \neq 0$ mempunyai akar-akar $z_{1}$ dan $z_{2}$. Akan dibentuk suatu persamaan kuadrat baru yang akar-akarnya $z_{1}+k$ dan $z_{2}+k$ untuk $k \in \mathbf{C}$ 
Misalakan $\alpha=z_{1}+k$ dan $\beta=z_{2}+k$, persamaan kuadrat baru yang akar-akarnya $\alpha$ dan $\beta$ adalah $z^{2}-(\alpha+\beta) z+(\alpha . \beta)=0$. Perhatikan bahwa

$$
\begin{aligned}
\alpha+\beta & =z_{1}+k+z_{2}+k \\
& =\left(z_{1}+z_{2}\right)+2 k \\
& =-\frac{b}{a}+2 k
\end{aligned}
$$

serta

$$
\begin{aligned}
\alpha \cdot \beta & =\left(z_{1}+k\right) \cdot\left(z_{2}+k\right) \\
& =\left(z_{1} \cdot z_{2}\right)+k\left(z_{1}+z_{2}\right)+k^{2} \\
& =\frac{c}{a}+k\left(-\frac{b}{a}\right)+k^{2}
\end{aligned}
$$

Dengan mensubtitusi ke persamaan $x^{2}-(\alpha+\beta) x+(\alpha \cdot \beta)=0$, diperoleh

$$
\begin{aligned}
& z^{2}-\left(-\frac{b}{a}+2 k\right) z+\left(\frac{c}{a}-k \frac{b}{a}+k^{2}\right)=0 \\
& a z^{2}+(b-2 a k) z+\left(c-k b+a k^{2}\right)=0
\end{aligned}
$$

\section{KESIMPULAN}

Diberikan persamaan kuadrat berkoefisien kompleks $a z^{2}+b z+c=0$ dengan $a, b, c \in \mathbf{C}$ dan $a \neq 0$. Akar-akar persamaan kuadrat dapat ditentukan sifat-sifatnya berdasarkan hubungan antar koefisiennya.

1. Jika $z_{1}$ adalah akar dari persamaan kuadrat dan $a, b, c \in \mathbf{R}$, maka $z_{2}=\bar{z}_{1}$ juga merupakan akar persamaan kuadrat. Tetapi jika $z_{1}$ adalah akar dari persamaan kuadrat dan $a, b, c \in \mathbf{C} \backslash \mathbf{R}$, maka $z_{2}=\bar{z}_{1}$ bukan merupakan akar persamaan kuadrat.

2. Persamaan kuadrat memiliki akar yang sama apabila $b^{2}=4 a c$.

3. Persmaan kuadrat memiliki akar kompleks yang saling konjugat apabila $a, b, c \in \mathbf{R}$ dan $b^{2}<4 a c$.

4. Persamaan kuadrat memiliki akar yang saling berkebalikan apabila $a=c$.

Selain itu, dapat juga ditentukan syarat agar persamaan kuadrat memiliki sebuah akar real dan syarat agar memiliki sebuah akar imajiner murni. Akar-akar persamaan yang diketahui dapat digunakan untuk menyusun persamaan kuadrat baru.

\section{DAFTAR PUSTAKA}

Andreescu T. dan Andrica D., 2010, Complex Numbers from A ...Z, $2^{\text {nd }}$ Edition. BirkhauserSpringer, New York.

Barnett, et.al., 2009, College Algebra, $9^{\text {th }}$ Edition. Mc Graw Hill, New York.

Hardy G. H., 1967, A Course of Pure Mathematics, $10^{\text {th }}$ Edition. Cambridge University Press, Cambridge.

Merino O., 2006, A Short History of Complex Numbers, http://www.math.uri.edu/

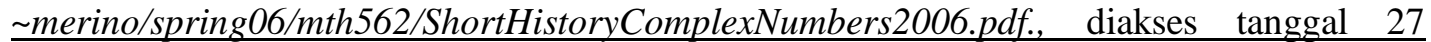
Agustus 2018. 
Sullivan M., 2012, College Algebra, $9^{\text {th }}$ Edition. Prentice Hall, USA.

Waerden B. 1985, A History of Algebra, Springer-Verlag, Berlin Heidelberg.

Zill D. G. dan Shanahan P. D., 2003, A First Course in Complex Analysis with Application. Jones and Bartlett Publisher, Massachusetts 